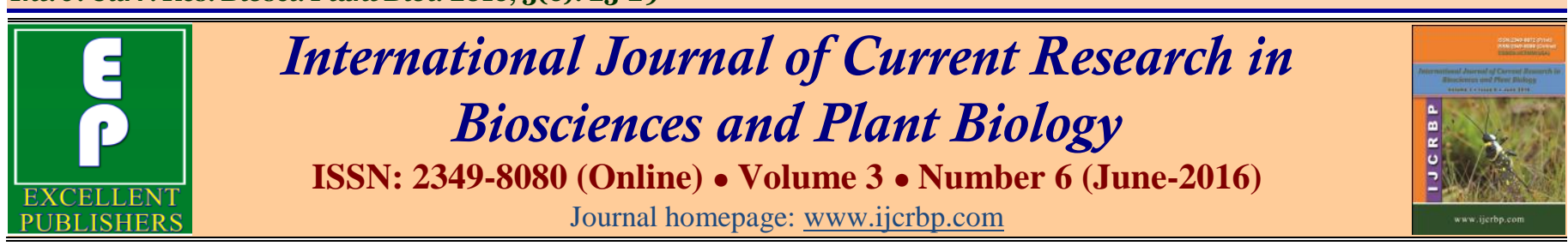

\title{
A Study of some Biochemical Parameters and ABCA1 Gene Polymorphism for Type-2-Diabetes Mellitus Patients
}

\author{
Sheereehan A. Mahdi ${ }^{1}$ and Talib AH Mousa ${ }^{2}$ \\ ${ }^{1}$ Biology Department, College of Sciences, Muthanna University, Samawah, Muthanna, Iraq \\ ${ }^{2}$ Biology Department, College of Education for Pure Sciences, Muthanna University, Samawah, Muthanna, Iraq \\ *Corresponding author.
}

\begin{abstract}
A b stract
The present study was undertaken to detect the possible association of V825I polymorphism in the ABCA1 gene and several environmental factors with serum lipid levels among 100 T2DM patients and 50 healthy control subjects. Each patients and controls are classified into three groups according to their BMI (18.5-24.9 normal, 2529.9 over weight and $\geq 30 \mathrm{~kg} / \mathrm{m}^{2}$ obese), and also classified into three groups according to their ages (40-49.9 G1, 50-59.9 G2, $\geq 60$ year G3). The genomic DNA extraction to PCR and PCR-RFLP assay was detected on gel electrophoresis. PCR was carried out to amplify $525 \mathrm{bp}$ fragment of ABCA1 gene contained V825I polymorphic position by using restriction enzyme Taq1. The presence of the cutting site indicates the A allele, while its absence indicates the $\mathrm{G}$ allele. Thus, the GG genotype indicates the absence of the site (band at $525 \mathrm{bp}$ ), GA genotype indicates the absence and presence of the site (bands at 525, 302 and 223bp) and AA genotype indicates the presence of the site (bands at 302 and $223 \mathrm{bp}$ ). The present study found that the frequency of GG genotype and G allele are higher in healthy controls compared to patients, converse to AA genotype which was higher in patients compared to healthy controls. The data also shows significant relationship between ABCA1 gene polymorphism with each of TG and VLDL $(p<0.01$ for each). Our results found that the frequency of GG genotype for overweight and obese and frequency of AA for obese are significantly higher $(p<0.05)$ in patients compared to healthy controls. The results confirmed that the frequency of GG genotype is significantly higher $(p<0.01)$ in healthy compared to patients according to the age of more than 50 year only. The results indicate the highly significant $(p<0.01)$ in frequency of GG genotype, higher in female patients compared to healthy controls. We have found the presence of significant relationship between $\mathrm{ABCA} 1$ gene polymorphism and serum levels of TG and VLD in patients. The frequency of A allele is lower than that of G allele in each male and female groups. The presence of significant differences of GG genotype with the advancement of age in patients group was observed. The results confirmed that $\mathrm{G}$ allele may be a protective factor against diabetes mellitus.
\end{abstract}

\section{Introduction}

Diabetes is an accumulated glucose in blood, it is one of the four main non communicable diseases (NCDs) identified by the World Health Organization (WHO), besides the cardiovascular disease, cancer, and chronic respiratory diseases (Unwin et al., 2010), it is a group of metabolic disease characterized by hyperglycemia from defects in insulin secretion (T1DM) or insulin action (T2DM) or both (Gao et al., 2010). World Health 
Organization reported that there are $(2.8 \%)$ in the world suffering from diabetes (Wild et al., 2004). The increasing number of individuals with T2DM indicates a global epidemic. Prevalence of the disease was estimated to be $2.8 \%$ in 2000 and is predicted to increase to $4.4 \%$ by the year 2030. Although the prevalence of diabetes is expected to increase in all age groups, it has been estimated that there will be a greater increase in the proportion of patients with diabetes who are aged 45-64 years (Adiseshiah, 2005). The problem of DM in Iraq is progressively increasing and every year large number of population implicate with this dame disease (Abedalrahman and Al-Hadithi, 2013). T2DM has a substantial genetic component and is thought to be polygenic in nature (Porchay et al., 2009; Lango et al., 2008). Several genes influence the underline level of glucose tolerance and thereby contribute to overall susceptibility to T2DM (Elbein, 2009). Genetic linkage analysis and association studies have identified several candidate genes contributing to T2DM.

Adenosine triphosphate-binding cassette transporter A1 (ABCA1) is a 2261-amino acid integral membrane protein. This is located on the chromosome 9 in the area 9q31.1 and encodes ABCA1 protein that is expressed in liver tissue, macrophages, intestines, lungs, etc. It is a cell membrane transporter and mediates the efflux of cholesterol, phospholipids, and other lipophilic molecules from cells; transfer of these molecules from peripheral cells to the liver as lipid-poor Apo lipoprotein A1,which is the first step in high-density lipoprotein (HDL) particle formation (Oram and Vaughan, 2006; Attie et al., 2001). ABCA1 gene has been reported to play an important role in cholesterol metabolism especially in high-density lipoprotein cholesterol (HDL) (Saleheen et al., 2006; Daimon et al., 2005). This gene expression is up-regulated by modified LDL (Langmann et al., 1999), cAMP (Abe et al., 2000). Animals and human studies documented that defects in the ABCA1 pathway are significant determinants of coronary artery disease (CAD) (Vergeer et al., 2010).

\section{Materials and methods}

\section{Study design and subjects}

Fasting Blood samples were collected from two groups. First, healthy group includes 50 individuals (median $=49$ years; min-max $=40-65$ years; 24females and 26 males). Control group was selected from patients without T2DM or other metabolic disorders like severe liver or renal dysfunction. Second group includes T2DM group, consisted of 100 patients $($ median $=56$ years; $\min$-max $=$ 45-65 years; 54 females and 46 males). The patients were recruited from Department of Internal Medicine, AlHussein Training Hospital, Al-Muthanna province/Iraq, between November 2014 to March 2015. Patients were diagnosed with diabetes mellitus based on the fasting blood glucose concentration (> $7 \mathrm{mmol} / \mathrm{L}$ ) and had developed the disease more than 3 years ago. This study was approved by the Scientific Committee of AlMuthanna University, College of Science, Biology Dept. Venous blood samples ( $8 \mathrm{~mL}$ each) were collected from each subject: $3 \mathrm{~mL}$ of EDTA sample, stored at $-20^{\circ} \mathrm{C}$, used for genotyping analysis, and $5 \mathrm{~mL}$ of serum sample, allowed to clot in gel test tube, centrifuged at $4000 \times \mathrm{g}$ for $5 \mathrm{~min}$ at room temperature, used for biochemical analysis. Body mass index (BMI) values were calculated retrospectively and categorized according to WHO recommendations (WHO, 1995).

\section{Determination of ABCA1 V825I gene polymorphism}

Genomic DNA was prepared from peripheral blood leukocytes, it was extracted using automated DNA extraction instrument (Magtration Technology, Japan). To detect the ABCA1 V825I genotypes, PCR-RFLP assay was developed. Each $25 \mu \mathrm{L}$ PCR implication mixture contained 5-200ng DNA, $10 \times$ PCR buffer $\left(1.8 \mathrm{mM} \mathrm{MgCl}_{2}\right) 2.5 \mu \mathrm{L}, 1 \mathrm{U}$ Taq polymerase, $2.5 \mathrm{mmol} / \mathrm{L}$ of each dNTP (Tiangen, Beijing, People's Republic of China) $2.0 \mu \mathrm{L}, 5 \mathrm{pmol} / \mathrm{L}$ of each primer $(0.5 \mu \mathrm{L})$. The paired primer sequences were: forward, 5'GGTAGCCCACCACTCCCCTAAAG-3'; reverse, 5'ATCAGCTGCCTGTCCTTGGACTA-3'.

PCR amplification reaction was under a cycling protocol (Labnet international Inc, Japan), of processing started with $95^{\circ} \mathrm{C}$ for $5 \mathrm{~min}$; and 30 cycles at $94^{\circ} \mathrm{C}$ for $30 \mathrm{sec}$, $60^{\circ} \mathrm{C}$ for $45 \mathrm{sec}$ and $72^{\circ} \mathrm{C}$ for $30 \mathrm{sec}$ and a final extension at $72^{\circ} \mathrm{C}$ for $5 \mathrm{~min}$ were followed. RFLP assay was performed using $10 \mathrm{U}$ of the appropriate restriction enzyme Tag1 per $10 \mu \mathrm{L}$ PCR products and incubated at $65^{\circ} \mathrm{C}$ for $1-4 \mathrm{hrs}$. RFLP products were directly separated by electrophoresis on $2 \%$ agarose gels and visualized with ethidium-bromide staining, ultraviolet illumination. Three genotypes could be determined after electrophoresis: genotype GG (525bp band), genotype AA (302 and 223bp bands) and genotype GA (525, 302 and 223bp bands).

\section{Statistical analysis}

Epidemiological data were recorded on a pre-designed form and managed with Excel software. All statistical 
analyses were performed with SPSS for Windows standard version 15.0 software. Quantitative variables were expressed as mean \pm standard deviation. Qualitative variables were expressed as percentages. Allele and genotype frequencies were determined by direct counting. Clinical data were compared between subjects with T2DM and normal by the unpaired Student's t-test. The genotype distribution of V825I polymorphism was compared between T2DM patients and normal subjects by the chi-square test. A $p$-value of 0.05 (two-sided) was accepted as the threshold for defining statistical significance.

\section{Results and discussion}

The general characteristics and serum lipid levels between patient and normal groups are summarized in Table 1. The levels of serum FBS, TC, TG, LDL,
VLDL, were higher in patients than in control subjects $(\mathrm{P}<0.05-0.001)$. There were no significant differences in the levels of BMI and HDL (P > 0.05 for both). The results are in agreement with a study regarding the role of lipid profiles in DM patients which is well established in many recent studies (Samatha et al., 2012; Hardev et al., 2008). Unbalanced metabolic states of diabetic patients that include hyperglycemia and insulin resistance might be lead to abnormalities in lipid profile (Hoffner, 2005). Patients with T2DM have many lipid abnormalities including elevated levels of (LDL), (VLDL) and low levels of (HDL) (Kumar and Clark, 2007), the results of this study are found to be traipses with our study. The present study also in a good agreement with study of Kappala (2012), which reveal high prevalence of hypercholesterolemia, high LDL-C, and low HDL-C levels which are well-known risk factors for CVD.

Table 1. Demographic characteristics of the study population in normal and patient groups.

\begin{tabular}{|c|c|c|c|c|c|}
\hline \multirow[b]{2}{*}{ Criteria } & \multirow{2}{*}{ Group } & \multicolumn{2}{|l|}{ Mean \pm SD } & \multirow{2}{*}{ t-test } & \multirow{2}{*}{$p$-value } \\
\hline & & Normal $(n=50)$ & Patients $(n=100)$ & & \\
\hline BMI $\left(\mathrm{kg} / \mathrm{m}^{2}\right)$ & & $30.36 \pm 6.47$ & $30.99 \pm 5.66$ & 0.618 & 0.537 \\
\hline FBS (mg/dl) & & $92.32 \pm 17.43$ & $226.67 \pm 88.35$ & 10.63 & 0.000 \\
\hline $\mathrm{TC}(\mathrm{mg} / \mathrm{dl})$ & & $168.98 \pm 41.12$ & $193.02 \pm 54.19$ & 2.76 & 0.006 \\
\hline $\mathrm{TG}(\mathrm{mg} / \mathrm{dl})$ & & $164.28 \pm 80.51$ & $197.77 \pm 102.97$ & 2.01 & 0.046 \\
\hline $\mathrm{HDL}(\mathrm{mg} / \mathrm{dl})$ & & $26.34 \pm 7.89$ & $28.17 \pm 8.56$ & 1.26 & 0.208 \\
\hline LDL (mg/dl) & & $109.78 \pm 33.54$ & $125.45 \pm 51.05$ & 1.96 & 0.050 \\
\hline $\operatorname{VLDL}(\mathrm{mg} / \mathrm{dl})$ & & $32.86 \pm 16.10$ & $39.55 \pm 20.59$ & 2.01 & 0.046 \\
\hline
\end{tabular}

\section{Electrophoresis and genotypes}

After the genomic DNA of the samples was amplified by PCR and imaged by $2 \%$ agarose gel electrophoresis, the purpose gene of 525 bp nucleotide sequences could be found in all samples, Fig. 1. The genotypes identified were named according to the presence or absence of the enzyme restriction sites, when a $G$ to A transversion at 825 locus of the ABCA1 gene. The presence of the cutting site indicates the A allele, while its absence indicates the $G$ allele (cannot be cut). Thus, the GG genotype is homozygote for the absence of the site (band at $525 \mathrm{bp}$ ), GA genotype is heterozygote for the absence and presence of the site (bands at 525, 302 and 223bp), and AA genotype is homozygote for the presence of the site(bands at 302 and 223bp) (Fig. 2).

The genotypic distribution of ABCA1 V825I polymorphism and frequency of $\mathrm{G}$ and $\mathrm{A}$ alleles in patients and controls are given in Table 2. We have observed that the frequency of each of GG and GA genotypes and $\mathrm{G}$ allele are higher in normal control than in patients group, converse to AA genotype and A allele which were higher in patients group, that made us think that $\mathrm{G}$ allele may be a protective factor against diabetes mellitus in Al-Muthanna population. However, this is a preliminary study and the results need to be confirmed in a larger studies. Other similar studies of ABCA1 C69T polymorphism that found higher frequency of the TT genotype and $\mathrm{T}$ allele in the controls in comparison with T2DM have been reported by Khalid et al. (2013) and Ergen et al. (2012).

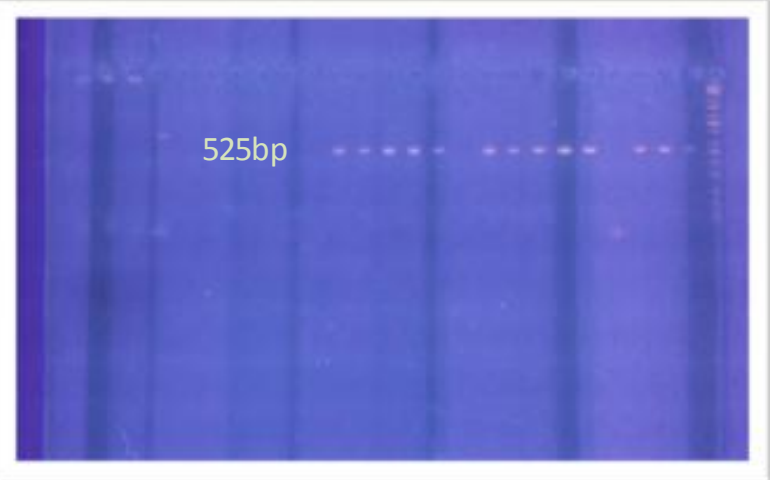

Fig. 1: PCR product of ABCA1 gene (525) genotype on 1\% agarose gel at 100 voltages for $40 \mathrm{~min}$ at 50 voltages for $30 \mathrm{~min}$. 


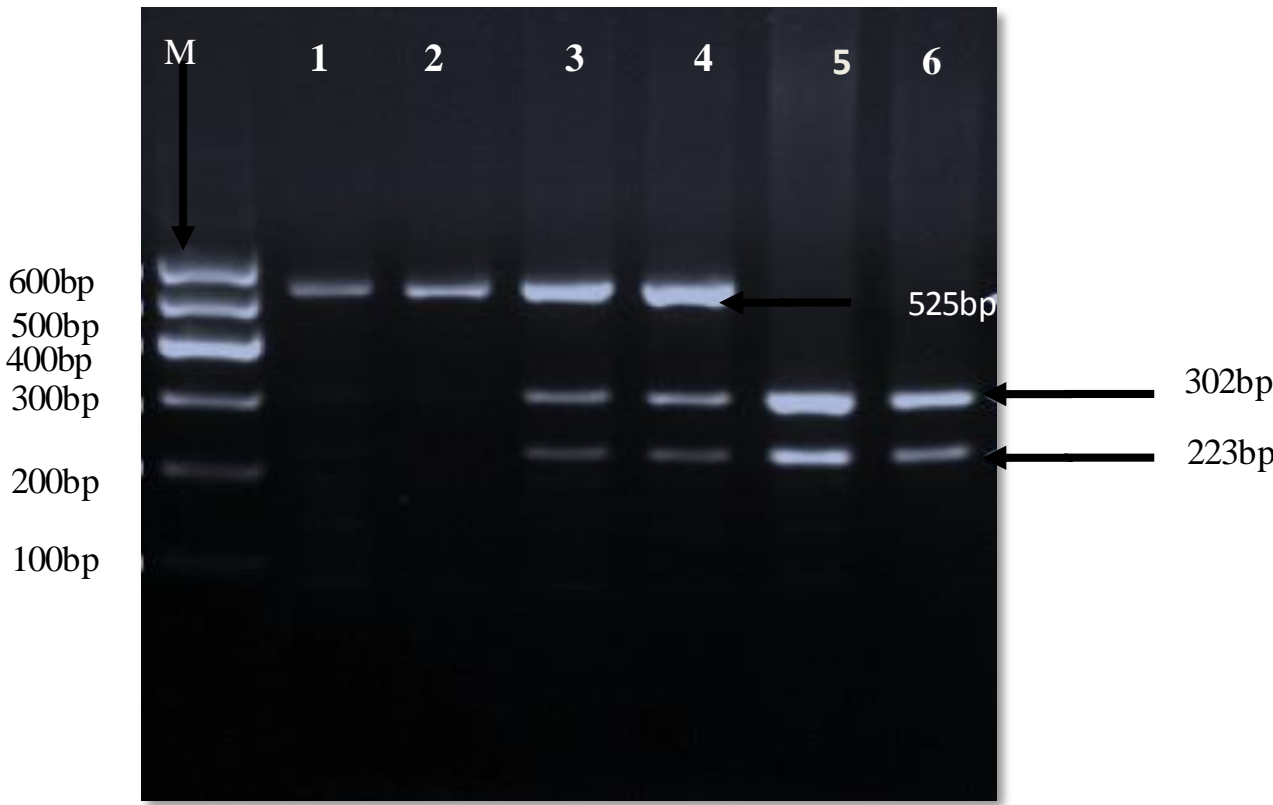

Fig. 2: Genotyping of ABCA1 gene in position 825. Lane M (2000-25bp) marker ladder; lanes 1 and 2 (GG genotype 525bp); lanes 3 and 4 (GA genotype 525bp and 302bp, 223bp); lanes 5 and 6 (AA genotype 302bp and $223 \mathrm{bp}$ ), on $1 \%$ agarose gel at 100 voltages for one hour.

Table 2. Distribution of ABCA1 C69T genotypes and alleles in normal and patient groups.

\begin{tabular}{lllll}
\hline \multirow{2}{*}{ ABCA1 genotypes } & Normal $(\mathbf{n}=\mathbf{5 0})$ & \multicolumn{2}{l}{ Patients $(\mathbf{n}=\mathbf{1 0 0})$} \\
\cline { 2 - 5 } & No. & Percent & No. & Percent \\
\hline GG & 29 & $58 \%$ & 56 & $56 \%$ \\
GA & 12 & $24 \%$ & 22 & $22 \%$ \\
AA & 9 & $18 \%$ & 22 & $22 \%$ \\
G & 70 & $70 \%$ & 134 & $67 \%$ \\
A & 30 & $30 \%$ & 66 & $33 \%$ \\
\hline
\end{tabular}

\section{Relationship between $\mathrm{ABC} 1$ gene polymorphism with plasma lipid levels, BMI, age and gender}

In the present study we have investigated the association of ABCA1 V825I polymorphism with T2DM in Al-Muthanna population. To the best of our knowledge this is the first study investigating the association of this polymorphism with T2DM in this province. The study showed significant relationship between ABCA1 gene polymorphism and lipid concentration (TG and VLDL) in patients, $(\mathrm{p}<0.05)$. We could not find any relationship between genotype frequency and other lipid serological markers and other parameters as in Table 3. ABCA1 has an important role in carrying cholesterol from peripheral tissues to liver (Ergen et al., 2012). Vergeer (2010) showed that heterozygous carriers of ABCA1 mutations displayed mild hyperglycaemia compared to non-carriers of similar age, sex and BMI. Epidemiological studies suggest that the risk of developing coronary heart disease for patient with T2DM is $2-4$ times higher than their counterparts without diabetes (Mooradian 2009). Earlier studies have investigated the effect of ABCA1 polymorphism on lipid-related diseases such as CAD and T2DM (Sheidina et al., 2004; Stefkova et al., 2004). This may increase risk for CHD (Frikke et al., 2008). Our results are disagreed with Saudi study which couldn't find any significant association between lipid profiles and ABCA1 gene polymorphism in Saudi population (Khalid et al., 2013), or China study which found that ABCA1 V825I gene polymorphism is associated with male serum HDL in the Han, and serum $\mathrm{TC}$ levels in the Bai $\mathrm{Ku}$ Yao, a population of Chinese ethnic groups (Cao et al., 2011). The present study also disagreed with the study concluded that an ABCA1 variant is associated with HDL level and early-onset T2DM in a specific Taiwanese population (Chieh et al., 2014). Our results are similar to Turkish study, where no association between this polymorphism and HDL concentration was reported (Ergen et al., 2012). 
Table 3. Distribution of FBS, lipid profile, BMI and age according to ABCA1 genotypes.

\begin{tabular}{|c|c|c|c|c|c|c|c|c|}
\hline \multirow{2}{*}{$\begin{array}{l}\text { ABCA1 } \\
\text { genotypes }\end{array}$} & \multicolumn{3}{|c|}{ Normal $(n=50)$} & \multirow{2}{*}{$p$-value } & \multicolumn{3}{|c|}{ Patients $(n=100)$} & \multirow{2}{*}{$p$-value } \\
\hline & GG (n=29) & GA(n=12) & AA $(n=9)$ & & GG $(n=56)$ & GA $(n=22)$ & AA $(n=22)$ & \\
\hline TC (mg/dl) & $169.14 \pm 38.62$ & $177.08 \pm 54.23$ & $157.67 \pm 29.13$ & 0.573 & $183.69 \pm 48.19$ & $200.95 \pm 56.82$ & $208.82 \pm 63.06$ & 0.135 \\
\hline HDL (mg/dl) & $26.83 \pm 7.66$ & $27.25 \pm 9.79$ & $23.56 \pm 5.83$ & 0.509 & $28.14 \pm 8.67$ & $27.82 \pm 8.03$ & $28.59 \pm 9.14$ & 0.956 \\
\hline LDL (mg/dl) & $110.88 \pm 33.55$ & $114.73 \pm 36.08$ & $99.64 \pm 31.69$ & 0.582 & $121.53 \pm 46.52$ & $130.50 \pm 43.93$ & $130.36 \pm 67.81$ & 0.692 \\
\hline $\operatorname{VLDL}(\mathrm{mg} / \mathrm{dl})$ & $31.43 \pm 16.24$ & $35.10 \pm 17.83$ & $34.47 \pm 14.49$ & 0.766 & $34.29 \pm 17.77$ & $42.64 \pm 21.51$ & $49.86 \pm 22.65$ & 0.007 \\
\hline
\end{tabular}

The present study confirmed that the frequency of genotypes and alleles are significantly different between patients and control groups according to Body mass index (BMI). The results observed that the frequency of GG genotype is significantly higher in patients compared with healthy controls in overweight $(p=0.014)$ and obese ( $p=0.013)$ and AA in obese only $(p=0.012)$, while there is no significant difference in frequency of GA in patients compared with normal groups as shown in Table 4. Our results are in accordance with a previous study which found an association of the ABCA1 variant with BMI (Villarreal et al., 2007), or with other results which also found the expression of ABCA1 was reduced in overweight and obese patients (Xu et al., 2009). Our study is also compatible with the study which concluded that an ABCA1 variant is associated with BMI and earlyonset T2DM in a specific Taiwanese population (Chieh et al., 2014).

Table 4. Distribution of ABCA1 genotypes and alleles in normal and patient groups according to BMI.

\begin{tabular}{llllll}
\hline ABCA1 Genotypes & Normal $(\mathbf{n}=\mathbf{5 0})$ & Patients $(\mathbf{n = 1 0 0})$ & BMI $^{*}$ & $\mathbf{X}^{\mathbf{2}}$ & $\boldsymbol{p}_{\text {-value }}$ \\
\hline GG & $4(8 \%)$ & $2(2 \%)$ & 1 & 0.667 & 0.414 \\
& $11(22 \%)$ & $26(26 \%)$ & 2 & 6.081 & 0.014 \\
GA & $14(28 \%)$ & $28(28 \%)$ & 3 & 4.667 & 0.031 \\
& --- & $3(3 \%)$ & 1 & --- & -- \\
AA & $5(10 \%)$ & $5(5 \%)$ & 2 & 0.000 & 1.000 \\
& $7(14 \%)$ & $14(14 \%)$ & 3 & 2.333 & 0.127 \\
G & $3(6 \%)$ & $3(3 \%)$ & 1 & 0.000 & 1.000 \\
& $4(8 \%)$ & $9(9 \%)$ & 2 & 1.923 & 0.166 \\
& $2(4 \%)$ & $10(10 \%)$ & 3 & 5.333 & 0.021 \\
A & $8(11.4 \%)$ & $7(5.2 \%)$ & 1 & --- & -- \\
& $27(38.6 \%)$ & $57(42.5 \%)$ & 2 & --- & -- \\
& $35(50 \%)$ & $70(52.2 \%)$ & 3 & -- & -- \\
\hline
\end{tabular}

$* 1=$ normal weight $\left(18.5-24.9 \mathrm{~kg} / \mathrm{m}^{2}\right), 2=$ over weight $\left(25-29.9 \mathrm{~kg} / \mathrm{m}^{2}\right), 3=$ obese $\left(\geq 30 \mathrm{~kg} / \mathrm{m}^{2}\right), X^{2}=$ Chi-square test.

The results show that the frequency of GG genotype is significantly higher in healthy controls compared to patients in the age of 40-49.9 year $(p=0.005)$, and highly significant in the age of more than 50 year $(p=0.00)$ in patients compared to healthy controls. The results also explained the absence of significant differences of GA and AA gene polymorphism for all age groups. Our study confirmed the presence of significant differences of GG genotype with the advancement of age in patients group, as shown in Table 5.

Our results explained that the frequency of GG genotype is significantly higher in female patients compared to healthy controls $(p=0.006)$, while there is no significant difference in frequency of GA and AA in patients compared with normal as shown in Table 6.

The results are disagreed with another study with reference to the absence of significant difference in the genotypic and allelic frequencies between males and females in selected Chinese ethnic groups (Cao et al., 2011). The present study also observed that the frequency of $\mathrm{G}$ allele in female is higher in patient than in control groups, conversely the frequency of that allele in male is higher in control than in patient groups. The results also confirmed the absence of significant 
differences of A allele frequency in male and female for each patient and control groups. Our results are disagreed with another study which found a very low frequency of
A allele in most subjects of European populations (Frikke et al., 2008). However, the present study and results need to be confirmed in further detailed studies.

Table 5. Distribution of ABCA1 genotypes and alleles in normal and patient groups according to the age.

\begin{tabular}{|c|c|c|c|c|c|}
\hline $\begin{array}{l}\text { ABCA1 } \\
\text { genotypes }\end{array}$ & Normal $(n=50)$ & Patients $(n=100)$ & Age* & $\mathbf{X}^{2}$ & $p$-value \\
\hline \multirow{3}{*}{ GG } & $22(44 \%)$ & $7(7 \%)$ & G1 & 7.759 & 0.005 \\
\hline & $5(10 \%)$ & $28(28 \%)$ & $\mathrm{G} 2$ & 16.030 & 0.000 \\
\hline & $9(18 \%)$ & $5(5 \%)$ & G1 & 1.143 & 0.285 \\
\hline \multirow[t]{2}{*}{ GA } & $3(6 \%)$ & $9(9 \%)$ & $\mathrm{G} 2$ & 3.000 & 0.083 \\
\hline & --- & $8(8 \%)$ & G3 & --- & --- \\
\hline \multirow[t]{3}{*}{$\mathbf{A A}$} & $3(6 \%)$ & $8(8 \%)$ & $\mathrm{G} 2$ & 2.273 & 0.132 \\
\hline & --- & $11(11 \%)$ & G3 & --- & --- \\
\hline & $53(75.7)$ & $19(14.4 \%)$ & G1 & --- & --- \\
\hline \multirow[t]{3}{*}{$\mathbf{G}$} & $13(18.6 \%)$ & $63(47.7 \%)$ & $\mathrm{G} 2$ & --- & --- \\
\hline & $4(5.7 \%)$ & $50(37.9 \%)$ & G3 & --- & --- \\
\hline & $21(70 \%)$ & $11(16.7 \%)$ & G1 & --- & --- \\
\hline
\end{tabular}

* G1=age (40-49.9 year), G2=age (50-59.9 year), G3=age ( $\geq 60$ year), $\mathrm{X}^{2}=$ Chi-square test.

Table 6. Distribution of ABCA1 genotypes and alleles in normal and patient groups according to the gender.

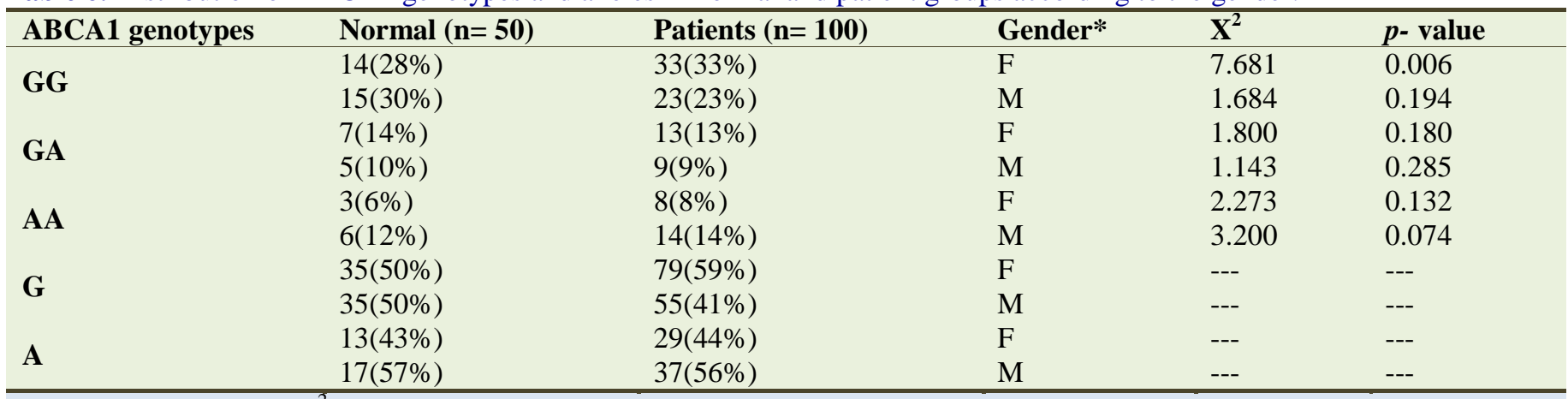

$* \mathrm{~F}=$ female, $\mathrm{M}=$ male, $\mathrm{X}^{2}=$ chi-square test.

\section{Conflict of interest statement}

Authors declare that they have no conflict of interest.

\section{References}

Abe, S., Suzuki, S., Wada, Y., Aburatani, H., Vance, D., Yokoyama, S., 2000. Characterization of apolipoproteinmediated HDL generation induced by cAMP in a murine macrophage cell line. Biochemistry. 39, 11092-11099.

Abedalrahman, S., Al-Hadithi, T., 2013. Nutritional assessment of hospitalized elderly diabetic patients in tikrit-iraq: a case- control study. Middl. East J. Age Ageing. 10, 1-8.

Adiseshiah, M., 2005. Effective care of patients with type 2 diabetes and dyslipidemia: A nurse's perspective. Diabetes Res. Clin. Pract. 68(Suppl. 2), S23-S27.

Attie, A., Kastelein, J., Hayden, M., 2001. Pivotal role of
ABCA1 in reverse cholesterol transport influencing HDL levels and susceptibility to atherosclerosis. J. Lipid. Res. 42, 1717-1726.

Cao, X., Yin, R., Wu, D., Lin, M., Lynn, H., Xi, H., Qing, L., Ting, Y., Wei, L., Shang, P., 2011. Genetic variant of V825I in the ATP-binding cassette transporter A1 gene and serum lipid levels in the Guangxi Bai $\mathrm{Ku}$ Yao and Han populations. Lipids Health. Dis. 10, 1-14.

Chieh, L., Wen, L., Tzu, W., Ching, C., Yung, C., Siu, T., Yu, H., Fuu, T., 2014. Association of adenosine triphosphatebinding cassette transporter A1 gene polymorphism with lipid profiles and early-onset type 2 diabetes. Science Asia. 40, 212-218.

Daimon, M., Kido, T., Baba, M., Oizumi, T., Jimbu, Y., Kameda, W., Yamaguchi, H., 2005. Association of the ABCA1 gene polymorphisms with type $2 \mathrm{DM}$ in a Japanese population. Biochem. Biophys. Res. Commun. 329, 205-210. 
Elbein, S., 2009. Genetics factors contributing to type 2 diabetes across ethnicities. J. Diabetes Sci. Tech. 3, 685689.

Ergen, H., Zeybek, U., Gok, O., Karaali, Z., 2012. Investigation of ABCA1 C69T polymorphism in patients with type 2 diabetes mellitus. Biochemia Med. 22(1), 114120.

Frikke, R., Nordestgaard, B., Jensen, G., Steffensen, R., Tybjaerg, A., 2008. Genetic variation in ABCA1 predicts ischemic heart disease in the general population. Arterioscler. Thromb. Vasc. Biol. 28, 180-186.

Gao, F., Yan, T., Zhao, Y., Yin, F., Hu, C., 2010. A possible mechanism linking hyperglycemia and reduced highdensity lipoprotein cholesterol levels in diabetes. J. Huazhong Univ. Sci. Technol. Med. Sci. 30, 318-321.

Hardev, S., Shyamal, K., Karanjit, S., 2008. A study of correlation between lipid profile and waist to hip ratios in patients with diabetes mellitus. Anthropol. 10(3), 215-218.

Hoffner, S. M., Sex, H., 2005. Obesity, fat distribution, type 2 diabetes and insulin resistance: epidemiological and clinical correlation. Int. J. Obes. Rel. Metabol. Disorder. 24, 556-558.

Kappala, S., 2012. Risk Factors and Blood Borne-Biochemical Markers in Type 2 Diabetes Mellitus. Ph.D. thesis, University of Central Lancashire.

Khalid, K., Imran, A., Nasser, M., Anjana, M., Vandana, S., Abdul KH., M., Kaiser, A., Yazeed, A., May, S., Mohammed, G., Rabbani, S., 2013. ABCA1 C69T gene polymorphism and risk of type 2 diabetes mellitus in a Saudi population. J. Biol. Sci. 38(5), 893-897.

Kumar, P., Clark, M., 2007. Diabetes Mellitus and other disorders of metabolism. Textbook of Medicine. Saunders, London. pp.1101-1130.

Langmann, T., Klucken, J., Reil, M., et al., 1999. Molecular cloning of the human ATP-binding cassette transporter 1 (hABC1): Evidence for sterol-dependent regulation in macrophages. Biochem. Biophys. Res. Commun. 257, 2933.

Lango, H., Palmer, C., Morris, A., Zeggini, E., Hattersley, A., McCarthy, M., Frayling, T., Weedon, M., 2008. Assessing the combined impact of 18 common genetic variants of modest effect sizes on type 2 diabetes risk. Diabetes. 57, 3129-3135.

Mooradian, A., 2009. Dyslipidemia in type 2 diabetes mellitus. Nat. Clin. Prac. Endocrinol. Metabol. 5, 150-159.

Oram, J., Vaughan, A., 2006. ATP-Binding cassette cholesterol transporters and cardiovascular disease. Circ. Res. 99, 1031-1043.
Porchay, I., Pean, F., Emery, N., Maimaitiming, S., Bellili, N., Travert, F., Mohammedi, K., Roussel, R., et al. 2009. Relationships between common polymorphisms of adenosine triphosphate-binding cassette transporter A1 and high-density lipoprotein cholesterol and coronary heart disease in a population with type 2 diabetes mellitus. Metabolism. 58, 74-79.

Saleheen, D., Nazir, A., Khatun, S., Haider, S., Frossard, P.M., 2006 A novel mutation in ABCA1 associated with low levels of HDL and type II diabetes mellitus. Int. J. Cardiol. 110, 259-260.

Samatha, P., Venkateswarlu, M., Sivaprambodh, V., 2012. lipid profile levels in type 2 Diabetes Mellitus from the tribal population of adlibbed in Andhra Pradesh, India. J. Clin. Diagn. Res. 6(4), 590-592.

Sheidina, A., Pchelina, S., Demidova, D., Rodygina, T., Taraskina, A., Toperverg, O., Berkovich, O., Demina, E., 2004. Allele frequency analysis of four single nucleotide polymorphisms located in promoted and 5'-untranslated regions of ABCA1 gene in young men-survivors from myocardial Infarction. Kardiologiia. 44, 40-45.

Stefkova, J., Poledne, R., Hubacek, J., 2004. Polymorphisms in ABCA1 transporter and plasma lipids. Physiol. Res. 53, 235-243.

Unwin, N., Gan, D., Whiting, D., 2010. The IDF Diabetes Atlas: providing evidence, raising awareness and promoting action. Diabetes Res. Clin. Pract. 87(1), 2-3.

Vergeer, M., Holleboom, A., Kastelein, J., Kuivenhoven, J., 2010. The HDL hypothesis: does high-density lipoprotein protect from atherosclerosis. J. Lipid. Res. 51(8), 20582073.

Villarreal, M., Aguilar, C., Rodriguez, M., Riano, D., Villalobos, M., Coral, R., et al., 2007. The ATP-binding cassette transporter A1 R230C variant affects HDL cholesterol levels and BMI in the Mexican population: association with obesity and obesity-related comorbidities. Diabetes. 56, 1881- 1887.

Wild, S., Roglic, Green, A., Sicree, R., King, H., 2004. Global prevalence of diabetes: estimates for the year 2004 and Projections for 2030. Diabetes Care J. 27(5), 1047-1053.

World Health Organization, 1995. Physical status: the use an interpretation of anthropometry: report of a WHO expert committee. WHO. Technical Report Series 854. pp.1-452.

$\mathrm{Xu}$, M., Zhou, H., Wang, J., Li, C., Yu, Y., 2009. The expression of ATP-binding cassette transporter A1 in Chinese overweight and obese patients. Int. J. Obes. 33, 851-856.

\section{How to cite this article:}

Mahdi, S. A., Mousa, T. A. H., 2016. A study of some biochemical parameters and ABCA1 gene polymorphism for Type-2-diabetes mellitus patients. Int. J. Curr. Res. Biosci. Plant Biol. 3(6), 23-29. doi: http://dx.doi.org/10.20546/ijcrbp.2016.306.003 